\title{
Procedimento para seleção de interfaces para produtos modulares baseado no ciclo de projeto de produtos
}

\author{
Régis Kovacs Scalice ${ }^{\mathrm{a} *}$, Luiz Fernando Segalin de Andrade ${ }^{\mathrm{b}}$, Fernando Antonio Forcellini ${ }^{\mathrm{c}}$ \\ ${ }^{a *}$ rkscalice@joinville.udesc.br, UDESC, Brasil \\ bluizsegalin@ifsc.edu.br, IFSC, Brasil \\ cforcellini@deps.ufsc.br, UFSC, Brasil
}

\begin{abstract}
Resumo
Este artigo aborda a definição de alternativas de interfaces durante desenvolvimento de produtos modulares. Entende-se por interfaces a fronteira entre os módulos que compõem o produto, bem como as interações existentes entre o meio-ambiente em que o produto está inserido e com seus possíveis usuários. Para realizar o projeto de interfaces é proposto um procedimento que auxilia na concepção de alternativas e em sua priorização, de forma a facilitar a tomada de decisão por parte da equipe de projeto. 0 procedimento proposto foi validado por sua aplicação no desenvolvimento de produtos modulares para o cultivo e beneficiamento de mexilhões em Santa Catarina. Os resultados obtidos demonstram o potencial da ferramenta.
\end{abstract}

Palavras-chave

Projeto modular. Projeto de interfaces. Desenvolvimento de produtos.

\section{Introdução}

As vantagens de desenvolver produtos em arquiteturas modulares são de conhecimento comum há algum tempo, por vários autores, incluindo Ulrich e Tung (1991), Ulrich (1995), Pahl et al. (2007), Kusiak e Huang (1996), entre vários outros, sendo que os principais benefícios da modularização de produtos podem ser resumidos em (KUSIAK; HUANG, 1996):

- Economia de escala;

- Aumento da possibilidade de modificação do produto/componente;

- Aumento da variabilidade do produto;

- Redução do tempo de entrega;

- Desacoplamento de riscos; e

- Diagnóstico, manutenção, reparo e descarte tornam-se mais fáceis.

Como se pode notar, tais vantagens estão associadas principalmente ao desacoplamento das funções elementares do produto (os módulos) e a possibilidade de oferecimento de soluções técnicas distintas para a mesma função (as variantes dos módulos). Nos últimos anos, os benefícios da modularidade vêm sendo abordados de diferentes maneiras. Para Fixson (2005), os custos unitários de produção podem ser reduzidos quando é possível reutilizar itens entre famílias de produtos ou ao longo de gerações, devido ao aumento de escala da produção. 0 autor ressalta, entretanto, que as economias de escala devem ser comparadas com o custo do esforço extra de projeto necessário ao reuso de itens. Tal visão é compartilhada por Wang (2009), que declara que, em geral, projetos modulares são utilizados para se obter mais variedade ou menores custos durante todas as fases do processo de desenvolvimento de produto.

Wiendahl et al. (2007), ao discutirem flexibilidade e capacidade de modificação de sistemas de manufatura, apontou a modularidade dentre outros cinco elementos capazes de obter tais características ainda durante as fases de projeto. 
A modularidade de produtos também desempenha um importante papel em termos de sustentabilidade ambiental. Para Seliger et al. (2008) e Seliger, Kernbaum e Zettl (2006), o projeto modular é considerado chave para a capacidade de adaptação e reconfiguração de um produto, facilitando sua desmontagem e remontagem, sendo que as interfaces desempenham um papel central nessa tarefa. Em Seliger, Kernbaum e Zettl (2006) também é ressaltado que o projeto modular é um dos elementos-chave que ampliam as possibilidades de remanufatura de produtos.

Tseng, Chang e Li (2008) apontam que a solução para o problema da poluição ambiental recai no projeto de produtos, sendo proposta pelo autor uma metodologia para avaliar a modularidade de produtos sob o ponto de vista de seu ciclo de vida.

Para que tais ações sejam possíveis, ou seja, para que sejam garantidos o intercâmbio e a separação entre módulos, suas interfaces devem ser adequadamente planejadas. Hölttä e Otto (2005) ressalta que, sem apoio à decisão adequado, engenheiros tendem a julgar interfaces sob a luz de sua própria experiência, o que pode deixar de lado alguns dos elementos de contorno do projeto de interfaces.

Vários autores atestam a importância de um correto e completo projeto das interfaces de um produto. Chen e Liu (2005) apontam que as interfaces entre módulos desempenham um importante papel no planejamento do produto e na concretização de processos, uma vez que é através delas que módulos podem ser substituídos, atualizados e ter suas funcionalidades alteradas.

Fixson (2005) aponta a complexidade da interface como um elemento crítico para a viabilidade de reuso de componentes e recomenda a simplificação da mesma. Para ilustrar a importância de tais ações de redução de complexidade, o autor cita o exemplo das interfaces de componentes eletroeletrônicos, que consistem em sua grande maioria de conexões tipo encaixe, fáceis de montar e que não apresentam possibilidade de erro. Fixson (2005) também alerta para o fato de que o tipo de interface entre componentes pode afetar a extensão na qual as estratégias de adiamento e de customização tardia podem ser realizadas.

0 uso de interfaces simples e no menor número possível também é um dos objetivos apontados por Neugebauer, Denkena e Wegener (2007) para o desenvolvimento de unidades modulares autônomas em produtos mecatrônicos, permitindo a substituição rápida de módulos quando necessário. Wiendahl et al. (2007) apontam que a utilização de interfaces uniformes facilita a compatibilidade de um sistema de manufatura flexível ou modificável, pois permite separar ou integrar diferentes elementos de fabricação.
Alizon, Shooter e Simpson (2007) afirmam que a especificação das interfaces entre módulos depende de diferentes parâmetros, tais como tecnologia, ciclo de vida, etc. Curiosamente, ao proporem seu método para projeto de produtos modulares, focado na Design Structure Matrix (DSM), os autores não abordaram tal questão.

Este artigo apresenta uma proposta de procedimento para o desenvolvimento de interfaces entre módulos cujo objetivo é oferecer um conjunto de soluções contendo as tarefas e ferramentas necessárias para levantar as necessidades de cada interface entre módulos, propor soluções e permitir a escolha da solução mais adequada às necessidades dos módulos.

\section{Fundamentação teórica}

Dentro da perspectiva de projeto de produtos modulares é importante entender que características devem ser consideradas para o desenvolvimento das interfaces neste tipo de produto. Para vários autores (ISHIl, 1998; GERSHENSON; PRASAD; ALLAMNENI, 1999; NEWCOMB; BRAS; ROSEN, 1998; JIAO; GERSHENSON; MICHALEK, 2006; WHITNEY, 2004), as características de um produto modular estão relacionadas a diversos aspectos do ciclo de vida do produto:

- Projeto - conforme a estratégia da empresa, pode-se desenvolver um produto modular ou uma família de produtos que utilizam módulos similares com diferentes configurações;

- Processo - a padronização dos módulos provoca uma redução na variedade de processos, aumento do número de itens similares e redução nos custos de produção;

- Montagem - pela padronização das interfaces entre os módulos, reduzem-se o número de operações, os tempos e os custos de montagem;

- Uso - apesar de apresentar uma performance possivelmente pior se comparada à de uma arquitetura integral, os produtos modulares possuem uma arquitetura mais amigável do ponto de vista de reparo, manutenção e descarte; e

- Fina de vida - a fácil desmontabilidade, padronização e intercambiabilidade tornam o produto mais propenso à reutilização de componentes.

Todas essas características tornam o produto modular muito atrativo para a indústria. Assim, a literatura apresenta diversos estudos sobre o tema. Alguns deles (HÖLTTÄ; OTTO, 2005; VAN WIE et al., 2003; PEREIRA; WEINGAERTNER; FORCELLINI, 2005) apresentam estudos sobre as interfaces de produtos modulares. Essa ênfase ocorre porque, conforme aponta Ullman (2003), a complexidade ocorre nas interfaces. 
Dentro dessa perspectiva, Hölttä e Otto (2005) utilizam a complexidade das interfaces como medida de flexibilidade do produto. Isto porque é difícil reprojetar um produto sem interferir nas suas interfaces (e no restante dele), o que implica dizer que quanto mais desacoplado um produto, mais flexível ele se torna.

A flexibilidade entre módulos é importante, do ponto de vista da possibilidade de recombinação e modificação de módulos isolados, para garantir o lançamento de novos produtos. Assim, torna-se importante a consideração do desenvolvimento das interfaces entre os módulos, de forma a garantir um produto com vida mais longa no mercado, com pequeno tempo e baixo custo de desenvolvimento.

A importância das interfaces para o projeto modular tem sido evidenciada por vários autores. Erixon, Von Yxkull e Arnström (1996) afirmam que as interfaces apresentam uma influência vital no produto final e na flexibilização da variedade. Ullman (2003) aponta que este é um passo crítico quando se desenvolve um conceito porque as conexões ou interfaces suportam as funções entre componentes e determinam sua posição relativa e sua localização.

Miller e Elgard (1998) diferenciam interfaces e interações. Para os autores, interfaces são as fronteiras entre os módulos, enquanto que as interações descrevem as relações de entrada e saída entre os módulos, as quais precisam ser compatíveis.

Zeng (2004) estabelece o conceito de fronteira do produto como o conjunto de interações entre o produto e seu ambiente de trabalho. Ela está dividida entre fronteira estrutural - estrutura física compartilhada pelo produto e por seu ambiente de trabalho - e interações físicas - que incluem ações do ambiente ao produto e as respostas do produto ao ambiente. Apesar de o autor se referir à fronteira com o ambiente externo do produto pode-se entender como sendo as fronteiras existentes entre os módulos, ou seja, o local onde estarão as interfaces.

Para Hillström (1994), as interfaces são superfícies funcionais que têm a finalidade de unir dois ou mais módulos e podem ser definidas como superfícies que realizam ao menos uma das seguintes funções: providenciar suporte, transmitir força, localizar o componente na montagem, providenciar a localização para outros componentes na montagem e transmitir movimento.

A partir dessas definições pode-se constatar que há um senso comum, também compartilhado por Pimmler e Eppinger (1994), de que uma interface é uma região onde há um fluxo de energia, material, informação ou uma interação espacial entre dois módulos ou componentes, ao menos.
Whitney (2004) argumenta que a modularização, em muitas aplicações, é possibilitada pela padronização das interfaces, pois esta padronização está intimamente ligada ao desacoplamento funcional. Este desacoplamento acaba por auxiliar na redução da ocorrência de efeitos incidentais. Para o autor, a padronização das interfaces surge quando:

- As interfaces não são submetidas a grandes cargas de trabalho ou de tensão;

- Elas não desempenham uma função principal ou afetam o desempenho do produto;

- Não consomem muitos recursos do projeto, como espaço, por exemplo;

- É necessária economia de escala para sua manufatura; e

- Elas podem ser definidas e projetadas independentemente dos itens unidos por elas.

É importante destacar que o conceito interfaces está atrelado diretamente à definição de arquitetura do produto. Arquitetura do produto ou configuração do produto pode ser definida como a distribuição, estrutura ou arranjo das funções, dos componentes e das montagens dos componentes no produto. Seu estabelecimento envolve decisões que dividem o produto em componentes individuais e o desenvolvimento de sua localização e orientação.

Sob este aspecto, Ulrich (1995) coloca que diferentes arquiteturas para o produto terão diferentes tipos de interface. Mesmo entre os diferentes tipos de arquitetura modular apontados pelo autor (slot, bus ou sectional) pode haver necessidade de se utilizar diferentes tipos de interface.

0 aspecto mais importante da arquitetura dos produtos é a forma como suas funções são mapeadas em relação aos componentes físicos. Vários autores, incluindo Stone, Otto e Wood (2001), Greer, Jensen e Wood (2004) e Dahmus e Otto (2001), abordam a questão da arquitetura modular. Dentro desse contexto, Ulrich e Eppinger (2004) estabelecem um método composto de quatro passos para a definição da arquitetura do produto:

- Criação do layout ou esquema do produto;

- Agrupamento dos elementos do esquema do produto;

- Criação do esboço do layout geométrico; e

- Identificação das interações fundamentais e incidentais.

Como se pode notar, os autores incorporam a necessidade de identificação das interações entre os blocos desenvolvidos. Para isso, colocam como possibilidade a utilização de um gráfico de interações ou de uma matriz de interações, conforme a complexidade do produto. Também há que se diferenciar as interações entre fundamentais e incidentais. As interações 
fundamentais são aquelas onde existem conexões básicas entre os elementos, isto é, onde ocorrem os fluxos de material, energia e informação. Essas são, por assim dizer, as interações desejadas. Já as interações incidentais são aquelas que se originam de interações desconhecidas, ou mesmo resultantes de interações esperadas, mas com consequências inesperadas por influência de variáveis externas.

Pereira (2004) aponta a relevância de levar em conta as interações incidentais entre módulos para o desenvolvimento de sistemas de precisão reconfiguráveis. Para tanto, aponta a possibilidade de utilização de uma matriz de avaliação de interfaces na qual o projetista deve estabelecer as correlações existentes entre os módulos. Essa ferramenta é muito similar à apresentada por Erixon, Von Yxkull e Arnström (1996), sendo que a diferença entre ambas está em quais parâmetros de avaliação são utilizados pelos autores. Enquanto Pereira (2004) avalia as compatibilidades e interações existentes entre os módulos, Erixon, Von Yxkull e Arnström (1996) enfatizam a compatibilidade de formas e tempos de montagem. As matrizes apresentadas pelos autores se encontram respectivamente na Figura 1 e na Figura 2. Matrizes de interfaces de Pereira (2004, p. 83).

Em se tratando especificamente do projeto de interfaces, é necessário que sejam abordados diferentes pontos do desenvolvimento de produto. Isso porque, conforme Ullman (2003), diversos aspectos do desenvolvimento do produto estão interrelacionados. Para o autor, a definição da forma está diretamente relacionada à função do produto, à definição do material do mesmo e à sua produção, sendo essa última entendida como formada pelos processos de manufatura e montagem. Além disso, a própria determinação da forma deve envolver as restrições do produto, a sua configuração, suas conexões e seus componentes.

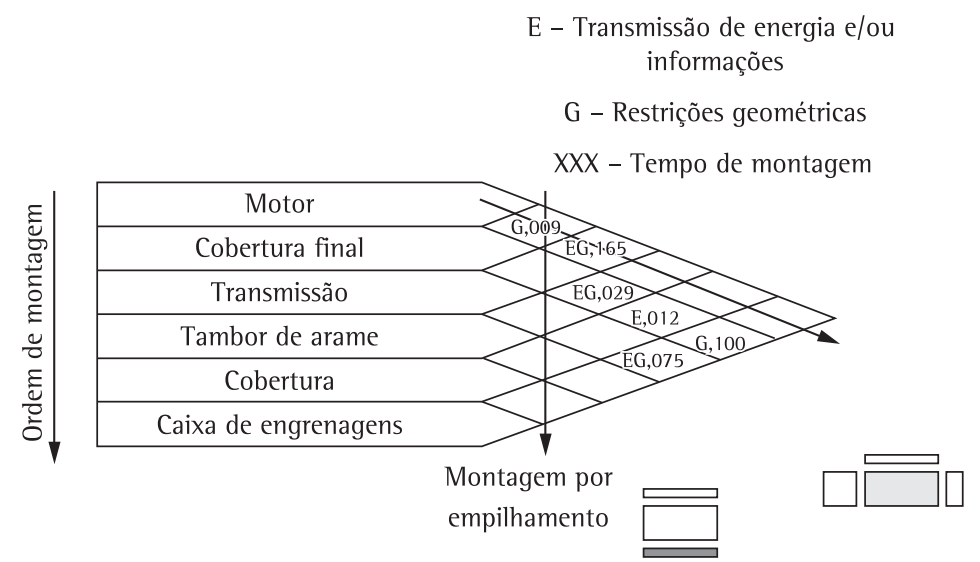

Figura 1. Matrizes de interfaces. Fonte: adaptada de Erixon, Von Yxkull e Arnström (1996, p. 3).

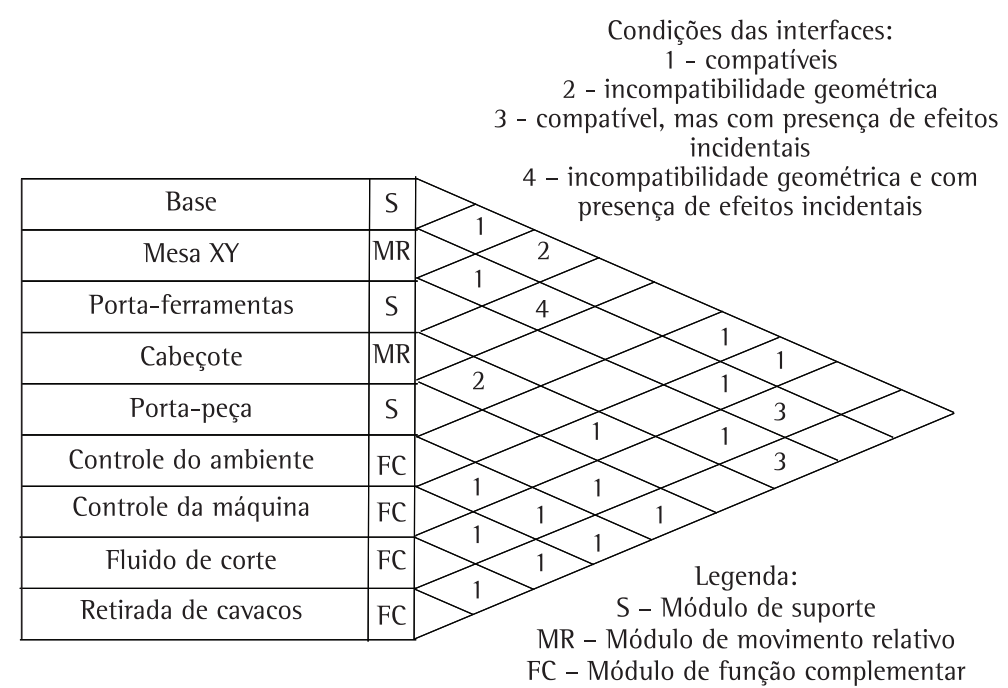

Figura 2. Matrizes de interfaces de Pereira (2004, p. 83). 
Siqueira e Forcellini (2001), ao abordarem a seleção e o projeto de uniões de componentes de plástico injetado, apontam a necessidade de realizar uma análise criteriosa e integrada de vários aspectos, incluindo: informações relativas ao processo de fabricação dos componentes; informações relativas à geometria e aos materiais dos componentes e uniões existentes; informações relativas às condições de uso do produto; recomendações de projeto de componentes e uniões de componentes; e informações relacionadas ao projeto e fabricação de moldes.

Além disso, para Ullman (2003), as restrições do produto são os muros ou o envelope para o produto. Portanto, o projetista deve iniciar com o conhecimento sobre as interfaces com outros objetos, pois muitos produtos devem trabalhar em relação com outros objetos existentes e imutáveis.

Com base nessas informações pode-se detectar a necessidade de, para a determinação das interfaces do produto, considerar todos os aspectos do ciclo de vida do produto. Isso se deve ao fato de que se está trabalhando com elementos que unem diferentes componentes e que interferem diretamente nos processos de manufatura, montagem, uso e reciclagem.

Outro aspecto importante a ser enfatizado em relação às interfaces refere-se à localização e orientação dos componentes. Ullman (2003) aponta que a primeira são as medidas dos componentes relativas à posição que ocupam no espaço e a segunda refere-se ao relacionamento angular entre os componentes. Assim, o projeto de configuração é um problema de localização e orientação.

Também é necessário ressaltar que as conexões determinam diretamente os graus de liberdade (DOF - degrees of freedom) entre os componentes e que cada interface deve ser pensada como restringindo algum ou todos esses graus de possibilidade de liberdade (BLANDING, 1999). Fundamentalmente, toda conexão entre dois componentes tem seis graus de liberdade - três translações e três rotações. É o projeto das conexões que determina quantos DOF o produto final terá. Não entender as conexões como restrições de DOF resultará num comportamento imprevisível. Além disso, o autor coloca algumas diretrizes para o desenvolvimento e o refino das interfaces entre componentes:

- As interfaces devem sempre refletir equilíbrio de forças e consistência de fluxos de energia, material e informação;

- Depois de desenvolver interfaces com objetos externos, considerar as interfaces das funções mais críticas;

- Tentar manter a independência funcional, no projeto, de uma montagem ou componente;
- Ser cuidadoso quando separar o produto em componentes isolados; e

- Criar e refinar interfaces pode forçar decomposições que resultam em novas funções ou podem encorajar o refinamento da decomposição funcional.

Assim, Ullman (2003) cita que, conforme as interfaces são refinadas, novos componentes e montagens são criados (ou tomam forma), ou seja, para o autor, os componentes evoluem primariamente das interfaces. Um passo para a avaliação de cada peça em potencial é determinar como cada novo componente muda a funcionalidade do projeto.

Um desenvolvimento correto das interfaces de um produto modular pode facilitar a montagem e desmontagem do produto. E também acaba por possibilitar a construção de diferentes produtos ou sistemas pela combinação dos diferentes módulos construtivos (BALDWIN; CLARK, 1997 apud CHEN; LIU, 2005). 0 desenvolvimento correto também pode reduzir custos de treinamento para a montagem, pois se pode primar por processos de montagem conhecidos.

Sanchez (1996) também enfatiza a padronização das interfaces entre módulos como potencializadora da flexibilidade do produto, pois com a mudança de poucos módulos pode-se obter uma família de produtos.

Com isso, o papel das interfaces dentro do projeto de um produto modular torna-se essencial para a obtenção dos melhores resultados possíveis.

Assim, de modo a projetar as interfaces, é necessário tratá-las como um novo problema de projeto. Isso quer dizer que o procedimento de projetar as interfaces de um produto deve envolver o levantamento dos requisitos dessas interfaces, de suas funções e dos princípios de solução para elas.

Visando facilitar o desenvolvimento de interfaces, alguns autores apresentaram sistemáticas de projeto voltadas ao tema. Siqueira e Forcellini (2001) apresentam uma sistemática para a seleção de uniões de peças de plástico injetado desenvolvida para a fase de projeto preliminar, que tem como entrada a concepção escolhida no projeto conceitual, conforme mostra a Figura 3.

Esse modelo busca desenvolver as interfaces entre componentes dentro do domínio de plásticos injetados seguindo a proposta de desenvolvimento de produtos de Pahl et al. (2007). Além disso, o autor detalha como desenvolver as interfaces por meio de tarefas específicas para cada fase. A limitação desse processo, além de ser desenvolvido no projeto preliminar de produtos, está em seu enfoque sequencial, voltado para aplicação no desenvolvimento de produtos de plástico injetado. 
Outro trabalho correlacionado ao projeto de interfaces é o de Pereira (2004), o qual apresenta um procedimento de projeto de interfaces para produtos reconfiguráveis. Nessa proposta, o autor desenvolve uma ferramenta chamada matriz de avaliação de interfaces, a qual serve para determinação das correlações e influências entre os módulos. Além disso, o autor apresenta os passos necessários para a avaliação das interfaces entre os módulos mostrados na Figura 4.

Este modelo levanta a adequabilidade das interfaces entre módulos, avalia a influência entre os módulos, verifica se há necessidade de realizar um reprojeto das interfaces mas fica preso, assim como o modelo

\begin{tabular}{|l|l|l|}
\hline \multicolumn{2}{|c|}{ Projeto } \\
conceitual
\end{tabular}

Figura 3. Etapas do processo de sistematização da seleção do tipo de união de componentes de plástico injetado. Fonte: Siqueira e Forcellini (2001, p. 3).

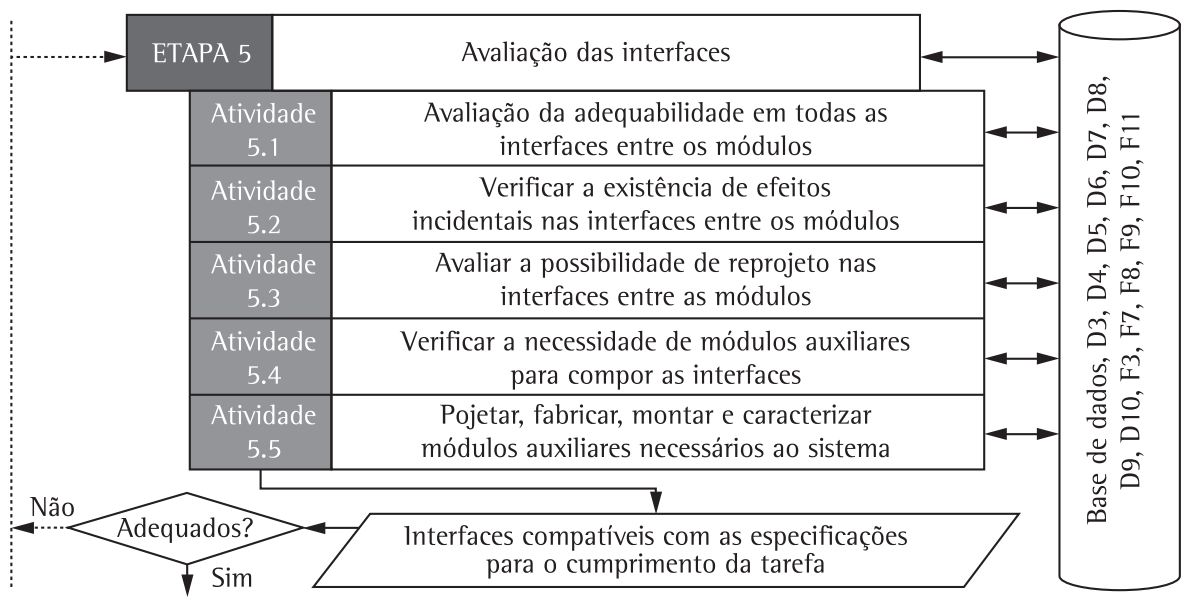

Figura 4. Passos necessários para a avaliação das interfaces entre os módulos. Fonte: Pereira (2004, p. 82). 
de Siqueira e Forcellini (2001), ao modelo tradicional de desenvolvimento de produtos. 0 mesmo também acontece na fase de projeto preliminar.

Hillström (1994) utiliza a teoria de projeto axiomático de Suh (1990), combinada às ferramentas de DFMA (Design for Manufacture and Assembly) convencionais, para criar um procedimento que auxilia o projetista a esclarecer como as interfaces entre módulos os influenciam, e para selecionar as melhores posições dessas interfaces. Para tanto, o autor se utiliza das informações contidas nas hierarquias funcionais e físicas, com intuito de esclarecer a interação entre função e interface.

Fixson (2005), por sua vez, criou uma forma de avaliação da arquitetura do produto que, apesar de ser um modelo de avaliação das interfaces, pode fornecer dados importantes para o levantamento de requisitos de interfaces. Esse modelo é baseado em alguns parâmetros do produto e serve como forma de analisar e avaliar a interface criada a fim de selecionar qual o melhor tipo de interface entre as possibilidades levantadas. Uma das métricas propostas pelo autor é baseada na característica das interfaces do projeto. Essa característica das interfaces diz respeito ao grau de acoplamento entre os elementos funcionais que compõem o produto. 0 autor aponta que a medida das interfaces deve ser realizada de maneira desagregada, para que permita uma investigação dos seus efeitos individuais. Para isso, o autor dividiu as informações a respeito das interfaces em três categorias: tipo, reversibilidade e padronização.

- Tipo de interface: está relacionado ao papel que ela desempenha na função do produto;

- Reversibilidade: diz respeito à capacidade de execução de mudanças no produto; e

- Padronização: relaciona-se à capacidade de substituição e elaboração de famílias de produtos.

Essas características possibilitam um mapeamento da arquitetura do produto, o que facilita a verificação da melhor alternativa de arquitetura para ele e, como dito anteriormente, fornece parâmetros de avaliação das interfaces criadas.

Neste trabalho é descrita uma proposta de procedimento de projeto de interfaces que busca englobar todas as etapas de desenvolvimento de interfaces de produtos modulares, sendo também exemplificada sua possibilidade de uso para projetos de família de produtos. Esse procedimento foi denominado procedimento de seleção de interfaces (PSI).

\section{Apresentação da proposta}

A proposta apresentada neste trabalho foi desenvolvida em três estágios. No primeiro, a elaboração da seleção de interfaces se deu durante o desenvolvimento do projeto de uma família de produtos modulares para o cultivo de mexilhões (SCALICE; FORCELLINI; BACK 2002), como parte da elaboração do método utilizado para o projeto da família de produtos. 0 segundo estágio se deu logo após o final do projeto de Scalice, Forcellini e Back (2002), com uma avaliação crítica dos resultados obtidos sob a óptica das interfaces obtidas nesse projeto. Tal ação levou ao terceiro e último estágio da pesquisa, no qual o método foi refinado, eliminando-se os pontos considerados falhos e resultando neste trabalho. Para a análise e reestruturação do modelo, a equipe de pesquisa foi ampliada, incluindo outro pesquisador da área de modularidade que também desenvolveu trabalhos relacionados ao projeto de interfaces. Dessa forma, a pesquisa, em relação a sua finalidade, pode ser caracterizada como pesquisa tecnológica, pois gera conhecimento para aplicação imediata pela indústria. Em termos de procedimento, a pesquisa pode ser definida como estudo de caso, pois baseou-se principalmente nos resultados obtidos de Scalice, Forcellini e Back (2002).

A estrutura do procedimento apresentado neste trabalho foi desenvolvida com base nas práticas de projetos conceituais adotadas por diferentes autores, dentre os quais se ressaltam Pahl et al. (2007), Rozenfeld et al. (2006) e Ulrich e Eppinger (2004). Outro ponto importante incorporado à proposta foi a contextualização do procedimento dentro do processo de desenvolvimento de produtos. Para tanto, foi utilizado como base o modelo do PDP de Rozenfeld et al. (2006), sendo o procedimento de seleção de interfaces proposto para utilização ao final do projeto conceitual do produto, logo após a seleção da arquitetura mais adequada para ele. Nesse momento têm-se definidos, junto com os princípios de solução que irão desempenhar as funções do produto, grande parte dos elementos da arquitetura de um produto, ou seja, seus sistemas, subsistemas e componentes. Esses itens, que ainda deverão ser aperfeiçoados durante o projeto detalhado do produto, serão complementados por outros componentes e sistemas relacionados às limitações construtivas do sistema concebido.

Como resultado, tem-se o procedimento de seleção de interfaces (PSI), cujas tarefas são ilustradas na Figura 5, assim como as fases associadas ao modelo de Rozenfeld et al. (2006).

O PSI inicia-se com a tarefa de levantamento dos requisitos de interface, que tem por objetivo determinar quais funcionalidades técnicas deverão ser desempenhadas entre os módulos definidos na fase de projeto conceitual, com base nas informações já disponíveis, como funções desempenhadas pelos módulos e princípios de solução adotados. Outras 


$\left.\left.\left.\left.\left.\left.\begin{array}{c}\text { Planejamento } \\ \text { do projeto }\end{array}\right\rangle \begin{array}{c}\text { Projeto } \\ \text { informacional }\end{array}\right\rangle \begin{array}{c}\text { Projeto } \\ \text { conceitual }\end{array}\right\rangle \begin{array}{c}\text { Projeto } \\ \text { detalhado }\end{array}\right\rangle \begin{array}{c}\text { Preparação } \\ \text { da produção }\end{array}\right\rangle \begin{array}{c}\text { Lançamento } \\ \text { do produto }\end{array}\right\rangle$

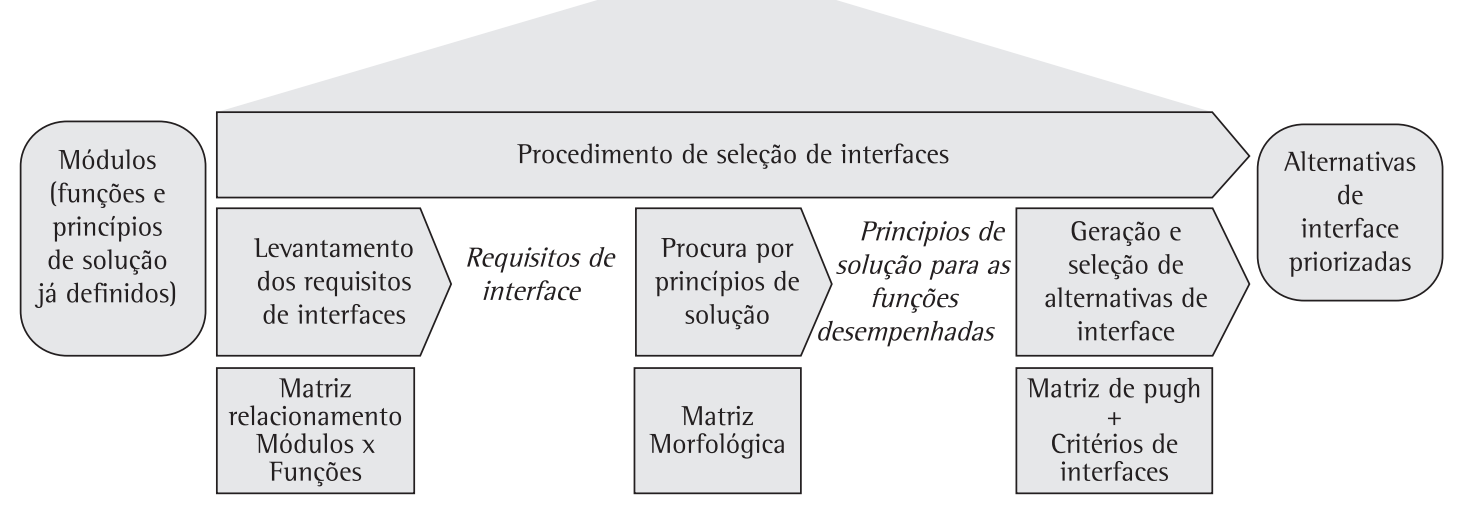

Figura 5. Procedimento de seleção de interfaces e sua localização no processo de desenvolvimento de produtos.

informações consideradas relevantes, se disponíveis, também podem ser levadas em conta, como processos de manufatura a serem adotados, desenho industrial e ergonomia. Para auxiliar, nessa tarefa é proposta a utilização de uma matriz relacionando (1) os módulos determinados na fase de projeto conceitual e (2) as funções para as interfaces, essas baseadas no trabalho de Hillström (1994), porém revistas e complementadas com outras informações:

- Transmitir energia: agrupa as possibilidades de troca de energia (forças, movimentos, ondas, eletricidade, etc.);

- Providenciar suporte: relacionado à existência de apoio entre módulos;

- Localizar o componente na montagem: facilitação da montagem entre dois módulos;

- Providenciar a localização para outros componentes na montagem: ligado à montagem dos módulos com outros componentes pertencentes a outros sistemas; e

- Transmitir informação: interações cognitivas entre módulo e usuário (sinais visuais, táteis, etc.) e comunicações módulo-módulo.

Para ilustrar a construção da matriz será utilizado como exemplo um telefone sem fio composto por dois módulos: base (módulo 1) e telefone (módulo 2), ilustrados na Figura 6. Nos cabeçalhos das colunas e linhas da matriz são listados os módulos do sistema. As cinco funções de interfaces são inseridas em cada uma das linhas. Também podem ser inseridas colunas específicas para analisar o relacionamento com o usuário (ser humano) e o ambiente ao redor. A matriz resultante para o exemplo descrito é apresentada na Figura 7.

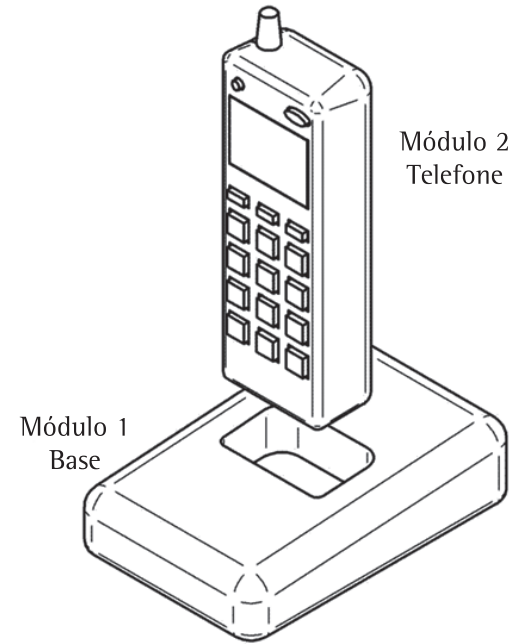

Figura 6. Exemplo - telefone sem fio.

Na Figura 7, as células da matriz consideradas desnecessárias foram eliminadas, ou seja, aquelas que correlacionam um módulo a si mesmo (módulo $1 \times$ módulo $\times$ e módulo $2 \times$ módulo 2), assim como as correlações redundantes (módulo $2 \times$ módulo 1). No exemplo apresentado, restam apenas a relação módulo $1 \times$ módulo 2 e as relações desses módulos com o usuário e o meio-ambiente.

0 próximo passo do preenchimento da matriz é feito atribuindo-se pesos às funções a serem desempenhadas pelas interfaces dos módulos. A matriz resultante para o exemplo didático proposto é apresentada na Figura 8, sendo as avaliações feitas listadas a seguir e ilustradas na Figura 9:

- Módulo $1 \times$ módulo 2 - há um forte relacionamento com as funções "providenciar suporte", "localizar o componente na montagem" e "transmitir energia", 


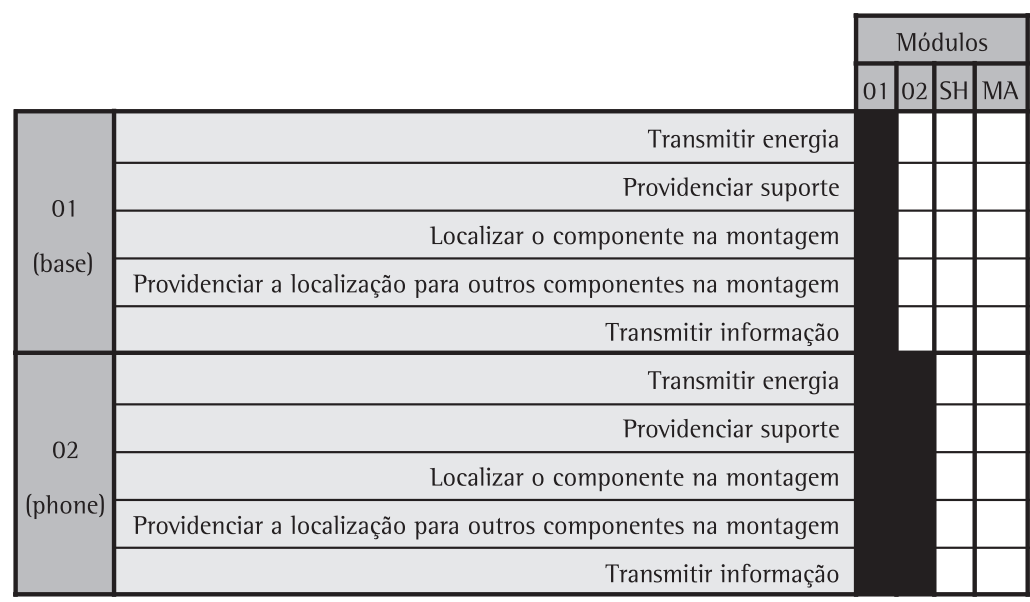

\begin{tabular}{|l|c|}
\hline \multicolumn{2}{|c|}{ Relacionamentos } \\
\hline Forte & $\bullet$ \\
\hline Médio & $\bigcirc$ \\
\hline Fraco & $\bigcirc$ \\
\hline
\end{tabular}

Ser humano SH

Meio-ambiente MA

Figura 7. Matriz para a determinação dos requisitos de interface.

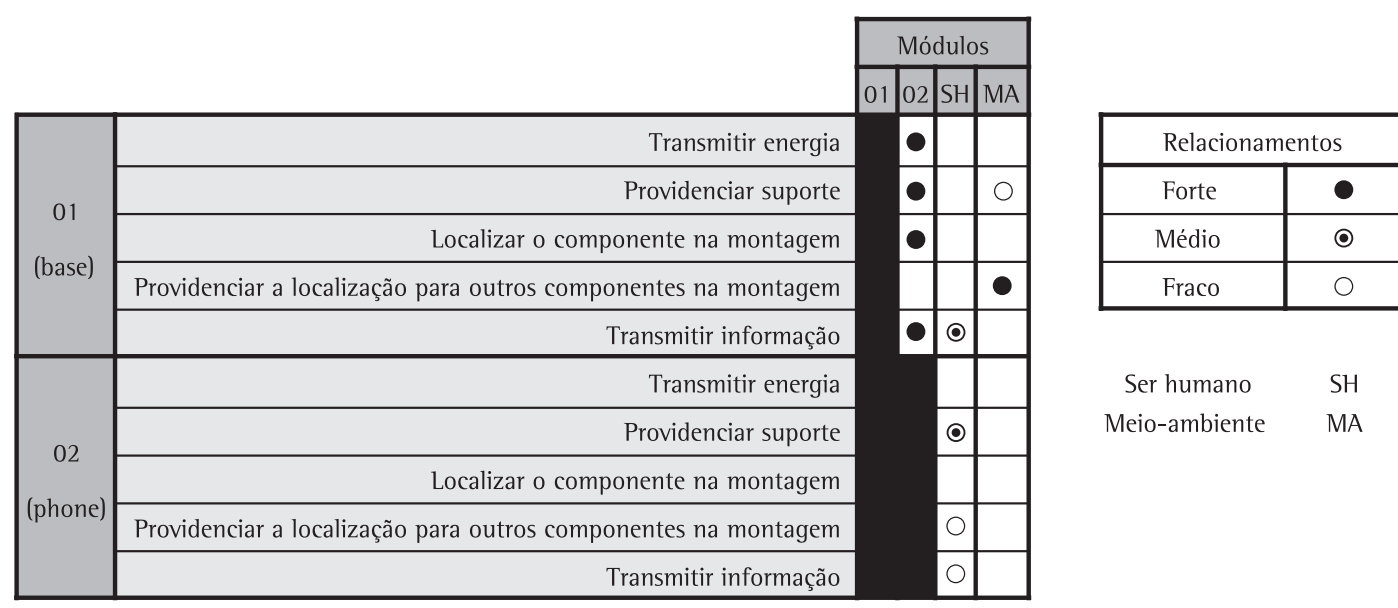

Figura 8. Preenchimento da matriz para determinação dos requisitos de interfaces.

afetas ao carregamento do telefone, e "transmitir informação", ligada ao uso;

- Módulo $1 \times$ ser humano - foi considerada uma média necessidade de informação de telefone em uso;

- Módulo $1 \times$ meio-ambiente - há uma forte necessidade de prover localização para entrada do conector da linha telefônica e da tomada de energia. Um relacionamento fraco foi adicionado visando a interação entre a base e seu local de colocação;

- Módulo $2 \times$ ser humano - para evitar quedas do telefone, foi considerada necessária a presença de meios para facilitar o posicionamento da mão e fornecer o suporte necessário ao telefone. Também há necessidade de comunicação de uso do telefone; e

- Módulo $2 \times$ meio-ambiente - não foram constatadas funções de interface.

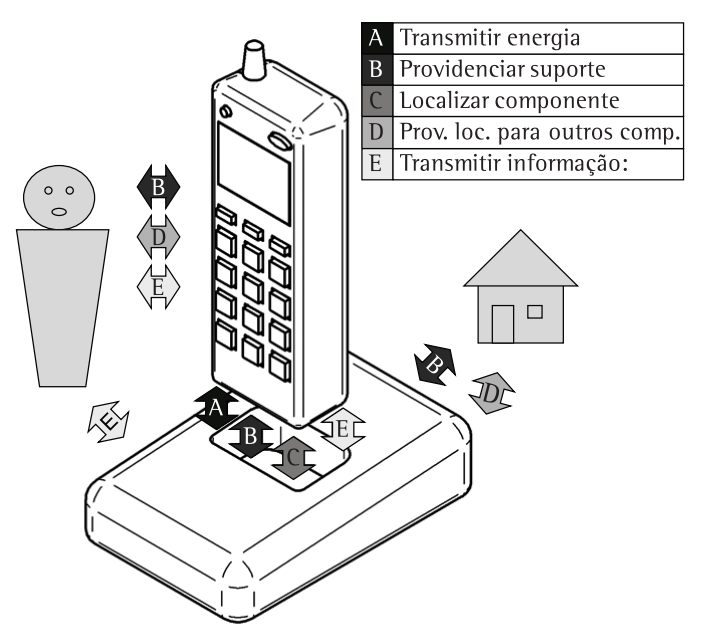

Figura 9. Representação ilustrativa das interfaces necessárias no exemplo. 
É importante destacar que as interfaces apresentadas nesse exemplo têm por objetivo apenas ilustrar o uso da ferramenta, podendo variar dependendo do escopo do projeto e da arquitetura adotada pelo produto. Finalizada essa tarefa, tem-se conhecimento de todas as funções desempenhadas pelas interfaces.

Iniciando a tarefa de procura por princípios de solução, deve ser feita uma busca em diferentes fontes, incluindo patentes, manuais técnicos, bases de dados científicas, bibliografia técnica, entre outras. Para auxiliar na organização das informações obtidas é proposto o uso de uma matriz morfológica, listando os princípios de solução levantados para cada uma das funções de interface, finalizando esta tarefa.

Como última tarefa do PSI tem-se a geração e seleção de alternativas de interface. Para gerar as alternativas de interface, os princípios de solução levantados na tarefa anterior devem ser combinados às funções de interfaces definidas na tarefa levantamento dos requisitos de interfaces. Para cada interface, podem ser definidas uma ou mais alternativas de projeto, resultando em uma coleção de opções de interfaces entre cada par de módulos.

Para a realização da seleção de cada interface é recomendado o uso de uma matriz de seleção (PUGH, 1991). Essa ferramenta permite analisar diferentes soluções para um determinado problema ao confrontar, em uma matriz, as alternativas de projeto (colunas) com critérios de comparação (linhas). Uma alternativa é selecionada como referência e é comparada individualmente com as demais, sendo essas consideradas melhores (+), piores (-) ou iguais (0) à alternativa de referência. Para auxiliar na avaliação das alternativas de interfaces, são propostos 11 critérios, apresentados no Quadro 1, aos quais devem ser atribuídos pesos de 1 a 5, partindo do menor para o maior grau de importância, de acordo com cada interface. Ao final dessa tarefa, as alternativas de projeto estão classificadas em ordem de prioridade, sendo as alternativas melhores classificadas aquelas que devem ser primeiramente selecionadas para detalhamento no projeto, sendo preteridas no caso de não se adequarem à arquitetura do produto.

No projeto detalhado, bem como nas demais fases, é importante considerar aspectos de intercambiabilidade com módulos de outras famílias e das evoluções técnicas do produto. Aspectos de dimensionamento e tolerâncias também são de grande importância para a manutenção dessa intercambiabilidade. Tais aspectos, ao serem considerados, podem levar à escolha de segundas ou terceiras opções dentre as melhores classificadas, ao invés da primeira.

\section{Avaliação do procedimento}

Como já comentado anteriormente, a avaliação do PSI se deu através de sua reaplicação no projeto de desenvolvimento de produtos modulares para o cultivo de mexilhões no estado de Santa Catarina, de Scalice, Forcellini e Back (2002). Nesse projeto, os esforços para a definição das interfaces se deram no final da fase de projeto conceitual, quando a arquitetura de forma modular já estava definida, porém antes de prosseguir com os detalhamentos do produto. Nesse ponto do projeto foram estabelecidos 16 módulos, sendo um deles uma fonte de potência única, denominada no projeto de FP, a ser compartilhada pelas oito configurações do produto, as quais realizam diferentes funções globais. 0 Quadro 2 lista as configurações de produto possíveis e suas funções, sendo os módulos ilustrados na Figura 10. É importante destacar que os módulos apresentados são provenientes do projeto conceitual do produto e, portanto, ainda carecem de todo o detalhamento e aperfeiçoamento que será realizado em fases posteriores.

Da tarefa de levantamento de requisitos de interface do PSI obteve-se a matriz apresentada no Quadro 3. 0 procedimento de preenchimento dessa matriz obedece as regras discutidas no tópico 3 deste artigo, não sendo consideradas, no entanto,

Quadro 1. Critérios propostos para comparação entre interfaces.

\begin{tabular}{cl}
\hline Critérios & \\
\hline Estanqueidade & Garantir o isolamento entre meios \\
Intercambiabilidade & Facilidade de substituição de módulos em uma mesma interface \\
Montabilidade & Facilidade na montagem do módulo \\
Desmontabilidade & Facilidade na desmontagem do módulo \\
Geometria & Importância em não serem efetuadas adaptações geométricas nos módulos para a implementação da \\
Material & interface \\
Forças, energias e movimentos & Edequação do material a ser empregado na interface ao produto na passagem de forças, energias e movimentos (perdas) \\
Produção & Facilidade de fabricação, montagem, transporte, etc. \\
Segurança e ergonomia & Influência na saúde do operador do equipamento \\
Custo & Necessidade de se minimizar o custo \\
Manutenção & Importância de se reduzir a periodicidade e a necessidade de manutenção das interfaces propostas \\
\hline
\end{tabular}


as interações com o usuário e o meio-ambiente. Tal decisão foi reflexo do nível de maturidade inicial da ferramenta, que ainda não incorporava tais possibilidades, além do fato de se tratar de produtos essencialmente mecânicos, com poucas interações com o usuário e o meio ambiente.

Algumas observações relevantes referentes à matriz apresentada no Quadro 3 devem ser feitas:

Quadro 2. Módulos estabelecidos durante o projeto conceitual da família de produtos modulares para o cultivo de mexilhões.

\begin{tabular}{|c|c|c|c|c|c|c|c|c|c|}
\hline & \multirow[b]{2}{*}{ Módulos (projeto conceitual) } & \multicolumn{8}{|c|}{ Configurações de produtos } \\
\hline & & 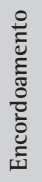 & 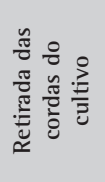 & 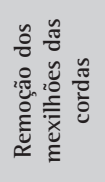 & 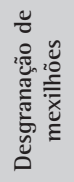 & 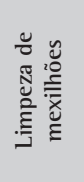 & 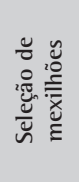 & 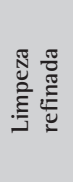 & 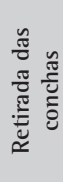 \\
\hline 1 & $\begin{array}{l}\text { Recepção de mexilhões introduzidos } \\
\text { no sistema }\end{array}$ & $x$ & - & - & $x$ & $x$ & $x$ & $x$ & $x$ \\
\hline 2 & Prolongador do módulo 1 & - & - & - & $x$ & $x$ & $x$ & $x$ & $x$ \\
\hline 3 & $\begin{array}{l}\text { Recebimento de mexilhões } \\
\text { processados }\end{array}$ & - & - & - & $x$ & $x$ & $x$ & $x$ & $x$ \\
\hline 4 & Separação de detritos & - & - & - & $x$ & $x$ & - & $x$ & - \\
\hline 5 & Tanque para recirculação de água & - & - & - & $x$ & $x$ & - & $x$ & - \\
\hline 6 & $\begin{array}{l}\text { Desgranação dos mexilhões por } \\
\text { agitação }\end{array}$ & - & - & - & $\mathrm{x}$ & $\mathrm{x}$ & $\mathrm{x}$ & $\mathrm{x}$ & $\mathrm{x}$ \\
\hline 7 & Escova para limpeza & - & - & - & - & $x$ & - & - & - \\
\hline 8 & Escova para limpeza refinada & - & - & - & - & - & - & $\mathrm{x}$ & - \\
\hline 9 & Separação de mexilhões por tamanho & - & - & - & - & - & $x$ & - & - \\
\hline 10 & $\begin{array}{l}\text { Retirada das conchas sem carne do } \\
\text { sistema }\end{array}$ & - & - & - & - & - & - & - & $x$ \\
\hline 11 & $\begin{array}{l}\text { Remove a carne do mexilhão já } \\
\text { desconchado do sistema }\end{array}$ & - & - & - & - & - & - & - & $x$ \\
\hline 12 & $\begin{array}{l}\text { Conduz mexilhões para corda de } \\
\text { engorda }\end{array}$ & $x$ & - & - & - & - & - & - & - \\
\hline 13 & $\begin{array}{l}\text { Carrinho para coleta e transporte de } \\
\text { cordas de mexilhões }\end{array}$ & $x$ & - & - & - & - & - & - & - \\
\hline 14 & Retirada de cordas de cultivo & - & $x$ & $x$ & - & - & - & - & - \\
\hline 15 & $\begin{array}{l}\text { Remove mexilhões presos às cordas } \\
\text { de engorda }\end{array}$ & - & - & $x$ & - & - & - & - & - \\
\hline FP & Fonte de potência & $x$ & $x$ & $x$ & $x$ & $x$ & $x$ & $x$ & $x$ \\
\hline
\end{tabular}
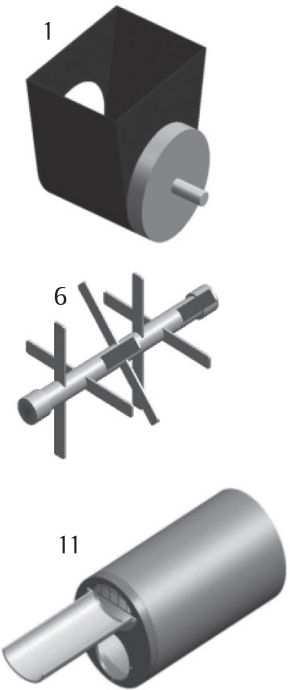
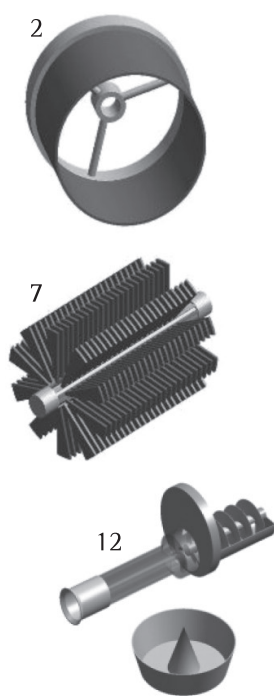
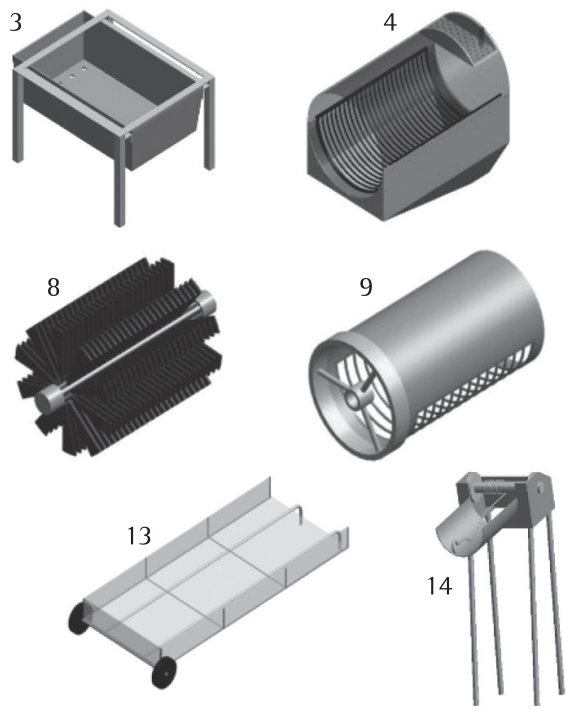

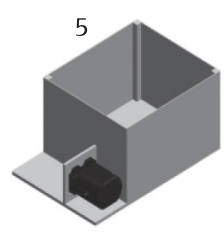

10

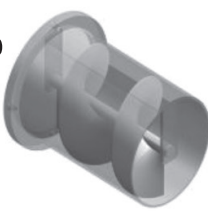

15

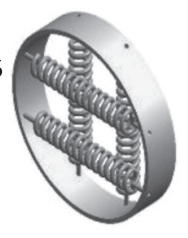

Figura 10. Representação dos módulos analisados, provenientes do projeto conceitual (SCALICE, 2003). 
- Foram suprimidas as linhas referentes aos módulos 9 a 16 por se considerar que já há informações suficientes para o entendimento do procedimento;

- As colunas em que não foram mapeadas interações também foram suprimidas;
- 0 módulo 3 sofre interação com ele mesmo, referente a necessidade de prover suporte para as caixas de pescado utilizadas para a coleta do material processado, resultado do princípio de solução adotado. Essas caixas, quando cheias, são substituídas por outras vazias;

Quadro 3. Matriz para determinação das funções desempenhadas entre as interfaces.

\begin{tabular}{|c|c|c|c|c|c|c|c|c|c|c|c|c|c|c|}
\hline \multirow[b]{2}{*}{ Módulo } & \multirow[b]{2}{*}{ Funções } & \multicolumn{13}{|c|}{ Módulos } \\
\hline & & 02 & 03 & 04 & 05 & 06 & 07 & 08 & 09 & 10 & 11 & 12 & 16 & FP \\
\hline \multirow{5}{*}{01} & Transmitir energia & - & - & - & - & 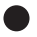 & 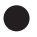 & 0 & - & - & - & 0 & - & 0 \\
\hline & Providenciar suporte & 0 & - & - & - & & 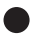 & O & - & - & - & 0 & - & 0 \\
\hline & Localizar o componente na montagem & O & - & - & - & 0 & O & O & - & - & - & 0 & - & 0 \\
\hline & Providenciar a localização para outros componentes & - & - & - & - & - & - & - & - & - & - & - & - & - \\
\hline & Transmitir informação & - & - & - & - & - & - & - & - & - & - & - & - & - \\
\hline \multirow{5}{*}{02} & Transmitir energia & & - & - & - & - & - & - & - & - & - & - & - & - \\
\hline & Providenciar suporte & & - & 0 & - & 0 & C & O & 0 & - & O & - & - & - \\
\hline & Localizar o componente na montagem & & - & 0 & - & 0 & O & O & 0 & - & O & - & - & - \\
\hline & Providenciar a localização para outros componentes & & - & O & - & 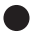 & 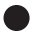 & 0 & 0 & - & O & - & - & - \\
\hline & Transmitir informação & & - & - & - & - & - & - & - & - & - & - & - & - \\
\hline \multirow{5}{*}{03} & Transmitir energia & & - & - & - & - & - & - & - & - & - & - & - & - \\
\hline & Providenciar suporte & & O & O & O & - & - & - & O & - & O & - & O & - \\
\hline & Localizar o componente na montagem & & - & 0 & 0 & - & - & - & 0 & - & O & - & O & - \\
\hline & Providenciar a localização para outros componentes & & - & - & - & - & - & - & O & O & - & - & - & - \\
\hline & Transmitir informação & & - & - & - & - & - & - & - & - & - & - & - & - \\
\hline \multirow{5}{*}{04} & Transmitir energia & & & & - & - & - & - & - & - & - & - & - & - \\
\hline & Providenciar suporte & & & & O & 0 & O & O & - & - & - & - & - & - \\
\hline & Localizar o componente na montagem & & & & O & 0 & O & O & - & - & - & - & - & - \\
\hline & Providenciar a localização para outros componentes & & & & O & 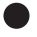 & 0 & 0 & - & - & - & - & - & - \\
\hline & Transmitir informação & & & & - & - & - & - & - & - & - & - & - & - \\
\hline \multirow{5}{*}{05} & Transmitir energia & & & & & - & - & - & - & - & - & - & - & 0 \\
\hline & Providenciar suporte & & & & & - & - & - & - & - & $\mathrm{O}$ & - & - & 0 \\
\hline & Localizar o componente na montagem & & & & & - & - & - & - & - & O & - & - & 0 \\
\hline & Providenciar a localização para outros componentes & & & & & - & - & - & - & - & - & - & - & - \\
\hline & Transmitir informação & & & & & - & - & - & - & - & - & - & - & - \\
\hline \multirow{5}{*}{06} & Transmitir energia & & & & & O & 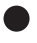 & O & - & O & - & - & - & - \\
\hline & Providenciar suporte & & & & & - & - & - & 0 & - & 0 & - & - & - \\
\hline & Localizar o componente na montagem & & & & & - & - & - & O & 0 & O & - & - & - \\
\hline & Providenciar a localização para outros componentes & & & & & - & - & - & 0 & - & 0 & - & - & - \\
\hline & Transmitir informação & & & & & - & - & - & - & - & - & - & - & - \\
\hline \multirow{5}{*}{07} & Transmitir energia & & & & & & 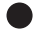 & O & - & - & - & - & - & - \\
\hline & Providenciar suporte & & & & & & - & - & - & - & - & - & - & - \\
\hline & Localizar o componente na montagem & & & & & & - & - & - & - & - & - & - & - \\
\hline & Providenciar a localização para outros componentes & & & & & & - & - & - & - & - & - & - & - \\
\hline & Transmitir informação & & & & & & - & - & - & - & - & - & - & - \\
\hline \multirow{5}{*}{08} & Transmitir energia & & & & & & & D & - & - & - & - & - & - \\
\hline & Providenciar suporte & & & & & & & - & - & - & - & - & - & - \\
\hline & Localizar o componente na montagem & & & & & & & - & - & - & - & - & - & - \\
\hline & Providenciar a localização para outros componentes & & & & & & & - & - & - & - & - & - & - \\
\hline & Transmitir informação & & & & & & & - & - & - & - & - & - & - \\
\hline
\end{tabular}

Relacionamentos Forte (O), Médio (○), Fraco (O) e Nulo (-). 
- Os módulos 6, 7 e 8 podem sofrer interações com outros módulos 6,7 e 8 quando utilizados de forma repetida em certas configurações de produtos (prolongadores); e

- 0 produto é essencialmente mecânico, não sendo necessária a transmissão de informações entre os módulos.

Seguindo os procedimentos da tarefa procura por princípios de solução, buscou-se levantar diversas possibilidades de princípios que atendessem tanto às funções desempenhadas pelas interfaces como às necessidades de projeto. Os princípios de solução estão apresentados no Quadro 4. Cabe ressaltar que para as funções localizar e providenciar localização de componentes foram agrupados os princípios de solução na matriz morfológica, dada a similaridade existente entre os princípios de solução observados.

Finalizando a aplicação do PSI, na tarefa geração e seleção de alternativas de interface, alternativas de projeto foram elaboradas combinando-se as funções de interfaces com os princípios de solução apresentados. Diversas alternativas de projeto puderam ser propostas, das quais algumas foram selecionadas por sua relevância e representatividade para ilustrar o procedimento. São elas:

- Módulo 1 × módulos 2 e 12 (Quadro 5) - o módulo 1 é responsável por grande parte da sustentação do equipamento, pela recepção do material a ser processado (mexilhões) e pela captura e transmissão dos movimentos e forças do módulo FP. Já os módulos 2 e 12 são responsáveis, respectivamente, por conduzir os mexilhões ao próximo módulo e realizar o encordoamento de mexilhões;

- Módulo 1 × módulos 6, 7 e 8 (Quadro 6) - os módulos 6 , 7 e 8 são necessários à realização das tarefas de separar fisicamente um mexilhão do outro e responsáveis pela limpeza e pela limpeza refinada dos mexilhões, respectivamente; e

- Módulo $2 \times$ módulos 4, 9 e 11 (Quadro 7) - o módulo 4 realiza a lavação de mexilhões, o 9, a separação entre mexilhões jovens e adultos e o 11, a separação entre carne e conchas.

Quadro 4. Princípios de solução levantados para as interfaces entre os módulos para os produtos para o cultivo de mxilhões - matriz morfológica.

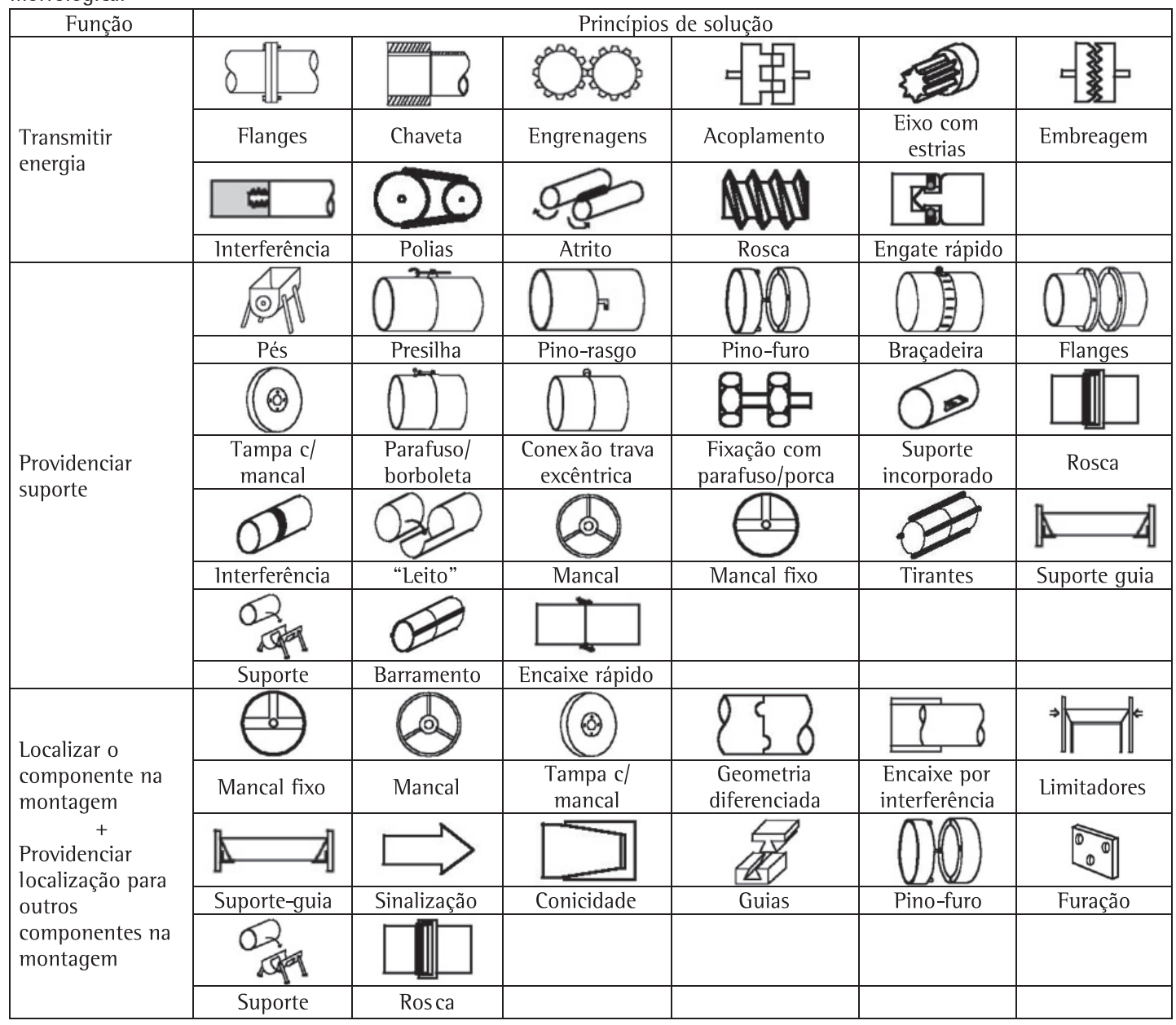


Finalizando o procedimento de seleção de interfaces, através do uso de matrizes de seleção ocorre a determinação das alternativas mais interessantes para cada interface entre módulos. Os pesos atribuídos aos critérios de seleção, já apresentados no Quadro 1, foram determinados com base no escopo do projeto da família como um todo e mantidos constantes em todas as análises. É importante destacar que também é possível a determinação desses critérios em separado, ou seja, reavaliar, a cada interface, os pesos para os critérios de seleção. Os resultados da seleção de alternativas de interface descritas na

Quadro 5. Alternativas de interface: módulo $1 \times$ módulos 2 e 12.

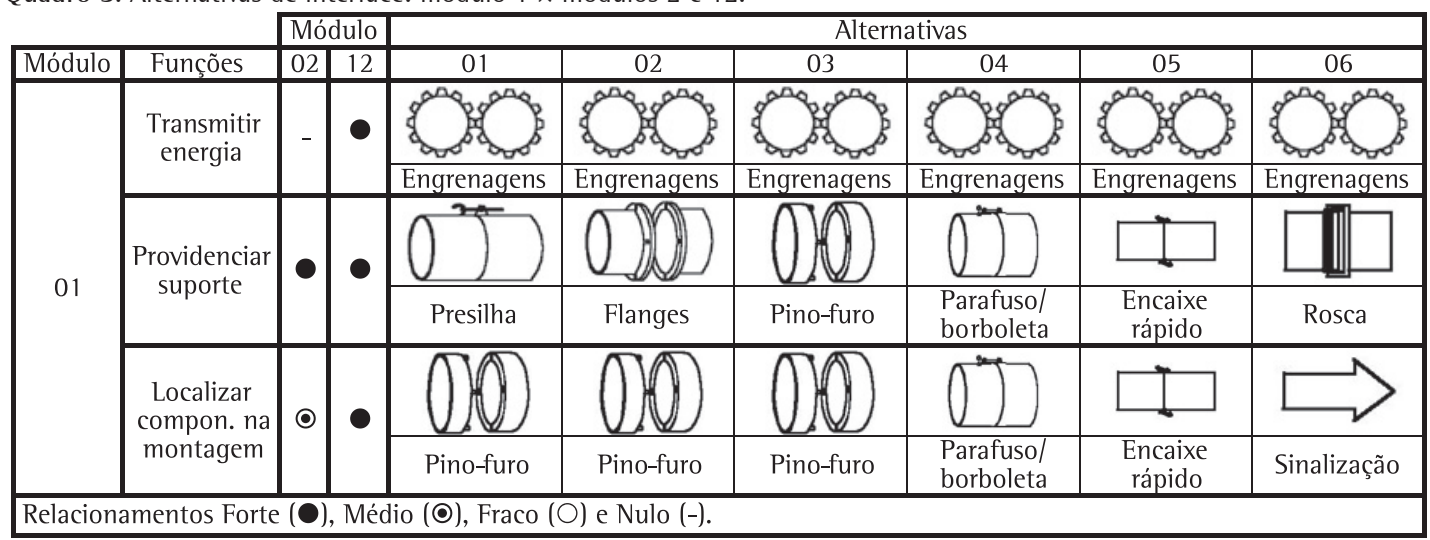

Quadro 6. Alternativas de interface: módulo $1 \times$ módulos 6, 7 e 8 .

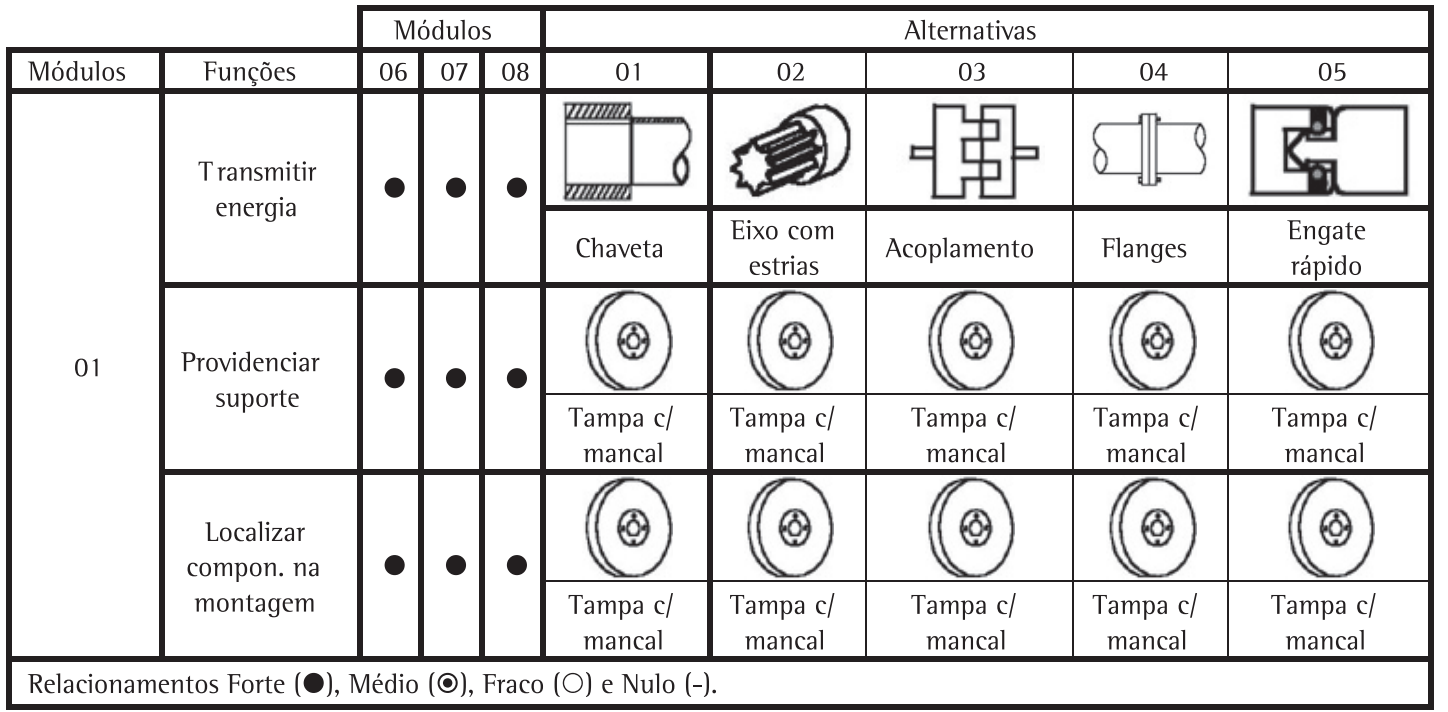

Quadro 7. Alternativas de interface: módulo $2 \times$ módulos 4, 9 e 11 .

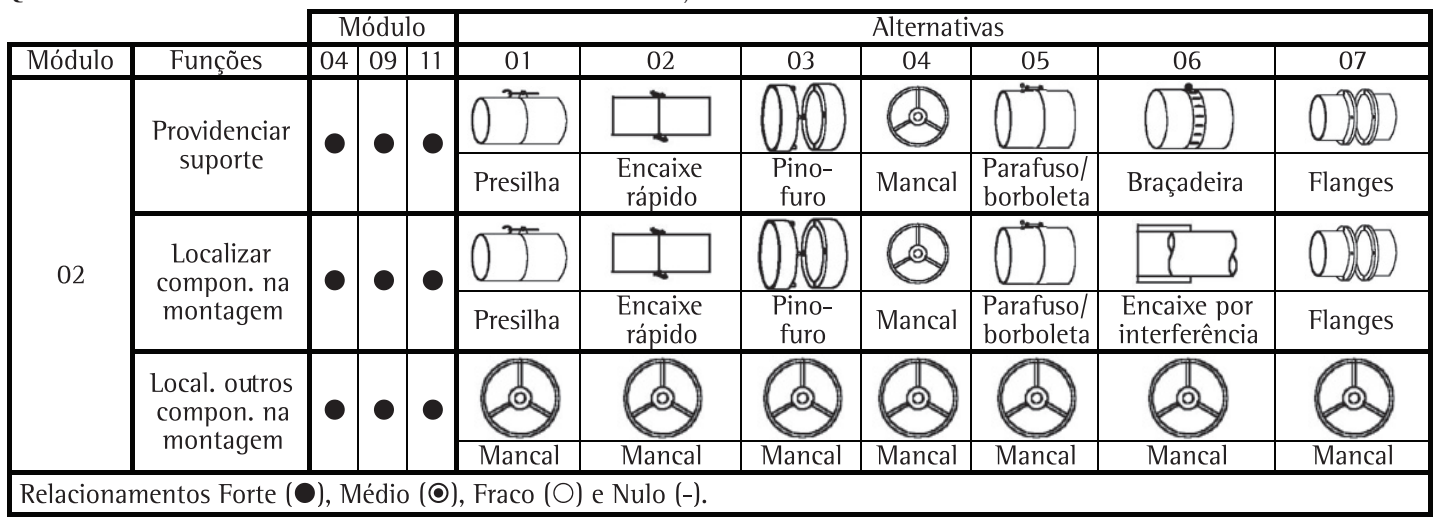


Figura 10 e Quadros 3 e 5 são ilustrados na Tabela 1, sendo realçadas em cinza as alternativas de interface melhor classificadas.

A consistência dos resultados obtidos pela aplicação do PSI pôde ser constatada durante a etapa de dimensionamento dos módulos, na qual se observou que as alternativas de interface propostas foram, em sua totalidade, empregadas no projeto dos módulos.
0 Quadro 8 ilustra os resultados finais, obtidos após dimensionamento realizado no projeto detalhado do produto, para as interfaces melhor classificadas na Tabela 1. Pode-se observar, por exemplo, que na interface entre o módulo M1 e o módulo 12 será utilizado um grampo de fixação, o qual se enquadra no princípio presilha, selecionado como melhor colocado na matriz de seleção do Quadro 7, na respectiva interface.

Tabela 1. Matrizes de seleção aplicadas às alternativas de interface.

\begin{tabular}{|c|c|c|c|c|c|c|c|c|c|c|c|c|c|c|c|c|c|c|c|}
\hline & & \multicolumn{6}{|c|}{$01 / 02-12$} & \multicolumn{5}{|c|}{ 01/06-07-08 } & \multicolumn{7}{|c|}{ 02/04-09-11 } \\
\hline & & \multicolumn{6}{|c|}{ Alternativas } & \multicolumn{5}{|c|}{ Alternativas } & \multicolumn{7}{|c|}{ Alternativas } \\
\hline Requisitos & Pesoa & 01 & 02 & 03 & 04 & 05 & 06 & 01 & 02 & 03 & 04 & 05 & 01 & 02 & 03 & 04 & 05 & 06 & 07 \\
\hline Estanqueidade & 4 & 0 & 1 & $\mathrm{R}$ & 0 & 0 & 2 & 0 & $\mathrm{R}$ & 0 & 0 & 0 & -1 & -1 & 0 & $\mathrm{R}$ & -1 & 1 & 0 \\
\hline Intercambialidade & 4 & 0 & 0 & $\mathrm{E}$ & 0 & 0 & 0 & 1 & $\mathrm{E}$ & 2 & 1 & 2 & 1 & 0 & 0 & E & 1 & 1 & -1 \\
\hline Montabilidade & 4 & 2 & -1 & $\mathrm{~F}$ & 1 & 1 & 1 & -1 & $\mathrm{~F}$ & 1 & -1 & 2 & 2 & 2 & 1 & $\mathrm{~F}$ & 1 & 0 & 0 \\
\hline Desmontabilidade & 4 & 2 & 0 & $\mathrm{E}$ & 1 & 1 & 1 & 0 & $\mathrm{E}$ & 0 & -1 & 1 & 2 & 1 & 0 & $\mathrm{E}$ & 1 & 0 & 0 \\
\hline Geometria & 5 & 1 & -1 & $\mathrm{R}$ & 1 & 1 & -2 & 0 & $\mathrm{R}$ & 0 & -1 & 0 & -1 & -1 & -1 & $\mathrm{R}$ & -1 & 0 & -2 \\
\hline Material & 4 & 0 & 0 & $\mathrm{E}$ & 0 & 0 & 0 & 0 & $\mathrm{E}$ & 0 & 0 & 0 & 0 & 0 & 0 & $\mathrm{E}$ & 0 & 0 & 0 \\
\hline Forças, energias e movimentos & 2 & 0 & 0 & $\mathrm{~N}$ & 0 & 0 & 0 & 0 & $\mathrm{~N}$ & 0 & 0 & -2 & 0 & 0 & 0 & $\mathrm{~N}$ & 0 & 0 & 0 \\
\hline Produção & 4 & 0 & 0 & $\mathrm{C}$ & 0 & 0 & -1 & 1 & $\mathrm{C}$ & 2 & -1 & -2 & 1 & 1 & -1 & $\mathrm{C}$ & 1 & -1 & -2 \\
\hline Segurança e ergonomia & 4 & -1 & 1 & E & -1 & -1 & 1 & 0 & $\mathrm{E}$ & 0 & -1 & 1 & -1 & -1 & 1 & $\mathrm{E}$ & -1 & 0 & 1 \\
\hline Custo & 5 & 0 & -1 & - & 0 & 0 & -1 & 2 & - & 1 & 0 & -1 & 1 & 1 & 2 & - & 1 & 1 & 0 \\
\hline \multirow[t]{4}{*}{ Manutenção } & 3 & 0 & 0 & - & 0 & 0 & 0 & 0 & - & 0 & 0 & 0 & 0 & 0 & 0 & - & 0 & 0 & 0 \\
\hline & $\Sigma(+)$ & 5 & 2 & 0 & 3 & 3 & 5 & 4 & 0 & 6 & 1 & 6 & 7 & 5 & 4 & 0 & 5 & 3 & 1 \\
\hline & $\Sigma(-)$ & -1 & -3 & 0 & -1 & -1 & -4 & -1 & 0 & 0 & -5 & -5 & -3 & -3 & -2 & 0 & -3 & -1 & -5 \\
\hline & $\Sigma$ & 4 & -1 & 0 & 2 & 2 & 1 & 3 & 0 & 6 & -4 & 1 & 4 & 2 & 2 & 0 & 2 & 2 & -4 \\
\hline \multicolumn{2}{|c|}{ Soma ponderada } & 17 & -6 & 0 & 9 & 9 & 1 & 14 & 0 & 25 & -17 & 7 & 16 & 8 & 9 & 0 & 8 & 9 & -18 \\
\hline
\end{tabular}

Quadro 8. Exemplos de soluções construtivas adotadas com base nos resultados do PSI.

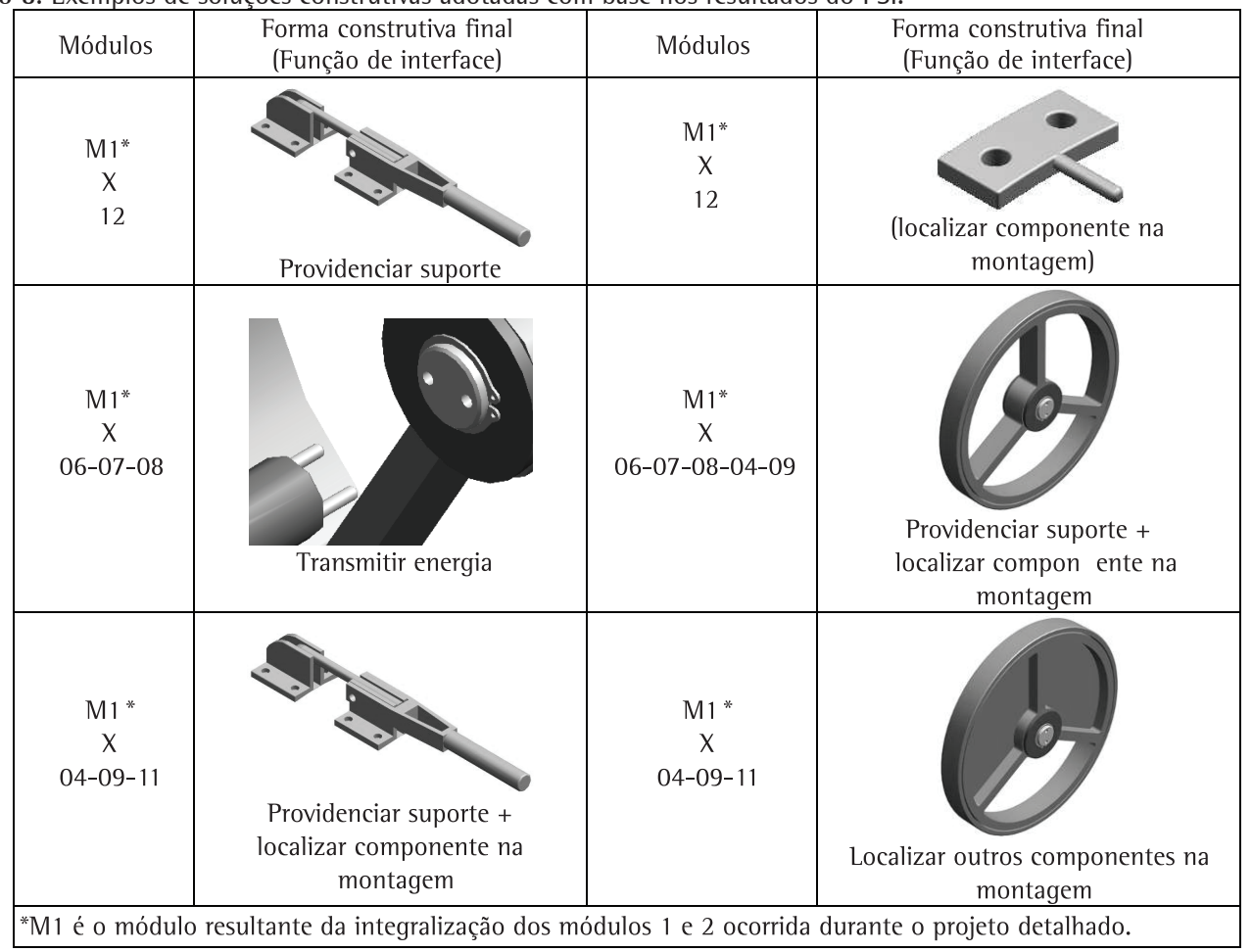


Uma observação final, porém de grande importância, é o fato de os resultados obtidos pela aplicação do PSI visarem apenas a orientação do projeto durante seu detalhamento. Um exemplo disso é o fato de que o módulo 2, cuja análise de interface foi apresentada na Figura 10 e Quadros 3 e 6, ter sido integrado ao módulo 1 em etapas posteriores do projeto, criando um único módulo. Ou seja, em termos práticos, as interfaces entre os módulos 1 e 2, apresentadas nas Figura 10 e Quadro 3, deixam de existir, e as interfaces restantes dos módulos 1 e 2 com os demais módulos passaram a ser assumidas por esse novo módulo, descrito no Quadro 8 como módulo M1. Outro exemplo do caráter orientativo do PSI é a eliminação, entre as interfaces, da função transmitir energia entre o módulo M1 (denominado 1 no Quadro 5) e o módulo 12, resultado de uma simplificação do projeto durante seu projeto detalhado.

\section{Conclusões}

Este artigo apresentou o procedimento de seleção de interfaces, ou PSI, o qual permite visualizar as interfaces necessárias para o produto, mapear as funções dessas interfaces e definir e classificar propostas de interface entre módulos. Grande parte da justificativa deste trabalho pode ser derivada das colocações de Alizon, Shooter e Simpson (2007), que afirmam que a especificação das interfaces entre módulos depende de diferentes parâmetros, tais como tecnologia, ciclo de vida, etc., sendo essa a visão que norteou a elaboração da proposta.

0 procedimento adotado se assemelha ao de projeto conceitual de produtos, partindo de uma análise das funções das interfaces, seguindo para a proposta de alternativas, finalizando com a determinação do grau de importância de cada uma. Para facilitar a realização desses procedimentos, foi proposta uma matriz para auxiliar na determinação das funções das interfaces e foram estabelecidos requisitos de interfaces para a realização da sua seleção.

Comparando-se o procedimento proposto com aqueles já encontrados na literatura, nota-se que em sua maioria os autores, ao abordarem a questão das interfaces, optam por apontar a importância das mesmas no projeto, incluindo algumas recomendações ao projetista. Até mesmo considerando os trabalhos de Erixon, Von Yxkull e Arnström (1996) e de Pereira (2004), os quais incluíram ferramentas para auxiliar na definição das interfaces em suas propostas, nota-se que os autores não possuem um método que abrange todo o ciclo de projeto, desde a análise (foco em suas ferramentas) até a seleção das alternativas de interface mais adequadas.

0 procedimento foi validado através de sua aplicação no projeto de produtos modulares voltados ao cultivo de mexilhões em Santa Catarina. Nessa aplicação observou-se que o PSI permite, de forma simples, apresentar soluções viáveis e adequadas à implementação de interfaces entre módulos. Além disso, o fato de ser possível propor alternativas para vários módulos simultaneamente ajuda no estabelecimento de padronização de interfaces. Também é importante destacar que definir as interfaces do produto auxilia no detalhamento do mesmo.

0 caráter orientativo da ferramenta deve ser ressaltado, uma vez que as soluções propostas para as interfaces são limitadas por aspectos como estrutura física dos módulos, viabilidade técnica de execução e padronização de interfaces, entre outras.

\section{Referências}

ALIZON, F.; SHOOTER, S. B.; SIMPSON, T. W. Improving an existing product family based on commonality/ diversity, modularity, and cost. Design Studies, v. 28, n. 4, p. 387-409, 2007. http://dx.doi.org/10.1016/j. destud.2007.01.002

BLANDING, D. L. Exact Constraint: Machine Design Using Kinematic Principles. New York: ASME Press, 1999.

CHEN, K. M.; LIU, R. J. Interface strategies in modular product innovation. Technovation, v. 25, n. 7, p. 771-782, 2005. http://dx.doi.org/10.1016/j.technovation.2004.01.013

DAHMUS, J. B.; OTTO, K. N. Incorporating lifecycle costs into product architecture decisions. In: ASME 2001 DESIGN ENGINEERING TECHNICAL CONFERENCES, 2001, Pittsburgh. Proceedings... Pittsburgh, 2001. p. 1-12.

ERIXON, G.; VON YXKULL, A.; ARNSTRÖM, A. Modularity - the Basis for Product and Factory Reengineering. Annals of the CIRP, v. 45, n. 1, p. 1-6, 1996. http://dx.doi. org/10.1016/S0007-8506(07)63005-4

FIXSON, S. K. Product Architecture Assessment: A Tool to link Product, Process, and Supply Chain Design Decisions. Journal of Operations Management, v. 23, n. 3-4, p. 345-369, 2005. http://dx.doi.org/10.1016/j. jom.2004.08.006

GERSHENSON, J. K.; PRASAD, G.; ALLAMNENI, S. Modular product design: a life-cycle view. Journal of Integrated Design and Process Science, v. 3, n. 4, p. 13-26, 1999.

GREER, J. L.; JENSEN, D. D.; WOOD, K. L. Effort flow analysis: a methodology for directed product evolution. Design Studies, v. 25, n. 2, p. 193-214, 2004. http:// dx.doi.org/10.1016/j.destud.2003.09.002

HILLSTRÖM, F. Applying Axiomatic Design to Interface Analysis in Modular Product Development. Advances in Design Automation - ASME, v. 4, n. 2, 1994.

HÖLTTÄ, K. M. M.; OTTO, K. N. Incorporating design effort complexity measures in product architectural design and assessment. Design studies, v. 26, n. 5, p. 463-485, 2005. http://dx.doi.org/10.1016/j.destud.2004.10.001

ISHIl, K. Modularity: A Key Concept in Product Lifecycle Engineering. In: MOLINA, A.; SÁNCHEZ, J. M. Handbook of Life-cycle Engineering: Concepts, Models, and Technologies. Springer, 1998. p. 511-530.

JIAO, J.; GERSHENSON, J. K.; MICHALEK, J. J. Special Issue on managing modularity and commonality in product and process development. Concurrent Engineering: Research and Application, v. 15, n. 2, p. 201-216, 2006.

KUSIAK, A.; HUANG, C. Development of modular products. IEEE Transactions on components, packaging, and manufacturing technology Part $A$, v. 19, n. 4, p. 523-538, 1996. http://dx.doi.org/10.1109/95.554934 
MILLER, T. D.; ELGARD, P. Defining Modules, Modularity and Modularization. In: IPS RESEARCH SEMINAR, 13., 1998, Fuglsoe. Proceedings... Fuglsoe, 1998.

NEUGEBAUER, R.; DENKENA, B.; WEGENER, K. Mechatronic Systems for Machine Tools. Annals of the CIRP, v. 56, n. 2, p. 657-686, 2007. http://dx.doi.org/10.1016/j. cirp.2007.10.007

NEWCOMB, P. J.; BRAS, B.; ROSEN, D. W. Implications of modularity on product design for the life cycle. Journal of Mechanical Design, v. 120, n. 3, p. 483-491, 1998. http://dx.doi.org/10.1115/1.2829177

PAHL, G. et al. Engineering design. A systematic Approach. Great Britain: Springer-Verlag London Limited, 2007.

PEREIRA, M. Metodologia de projeto para sistemas mecânicos de precisão reconfiguráveis. 2004. Tese (Doutorado em Engenharia Mecânica)-Universidade Federal De Santa Catarina, Florianópolis, 2004.

PEREIRA, M.; WEINGAERTNER, W. L.; FORCELLINI, F. A. Design methodology for reconfigurable precision systems applied to a sclerometer development. In: CIRP - INTERNATIONAL SEMINAR ON MANUFACTURING SYSTEMS, FLORIANOPOLIS, 38., 2005, Florianopolis. Proceedings... Florianopolis, 2005.

PIMMLER, T. U.; EPPINGER, S. D. Integration Analysis of Product Decompositions. In: ASME CONFERENCE ON DESIGN THEORY AND METHODOLOGY, 1994, Minneapolis. Proceedings... Minneapolis, 1994. p. 343-351.

PUGH, S. Total Design Integrated Methods for Successful Product Engineering. Adison Wesley Publishing Company, 1991.

ROZENFELD, H. et al. Gestão de Desenvolvimento de Produtos: uma referência para a melhoria do processo. São Paulo: Saraiva, 2006.

SANCHEZ, R. Strategic product creation: managing new interactions of technology, markets, and organizations. European Management Journal, v. 14, n. 2, p. $121-138,1996$. http://dx.doi. org/10.1016/0263-2373(95)00056-9

SCALICE, R. K. Desenvolvimento de uma Família de Produtos Modulares para o Cultivo e Beneficiamento de Mexilhões. 2003. Tese (Doutorado em Engenharia Mecânica)-Universidade Federal de Santa Catarina, Florianópolis, 2003.

SCALICE, R. K.; FORCELLINI, F. A.; BACK, N. B. Development of a modular product family for the mechanization of mussel farming and processing in Santa Catarina. Product: Management \& Development, v. 1, n. 3, p. 47-60, 2002. Disponível em: <http://pmd.hostcentral. com.br/revistas/vol_01/nr_3/v1n3a05.pdf>.

SELIGER, G.; KERNBAUM, S.; ZETTL, M. Remanufacturing Approaches Contributing to Sustainable Engineering.
Gestão \& Produção, v. 13, n. 3, p. 367-384, 2006. http:// dx.doi.org/10.1590/S0104-530X2006000300002

SELIGER, G. et al. Approaches to sustainable manufacturing. International Journal of Sustainable Manufacturing, v. 1, n. 1-2, p. 58-77, 2008.

SIQUEIRA, 0. C.; FORCELlINI, F. A. Sistemática para seleção do tipo de união de componentes de plástico injetados. In: CONGRESSO BRASILEIRO DE GESTÃO DE DESENVOLVIMENTO DE PRODUTOS, 3., 2001, Florianópolis. Anais... Florianopolis, 2001.

STONE, R. B.; OTTO, K. N.; WOOD, K. L. Product architecture. In: OTTO, K.; WOOD, K. Product Design: Techniques in Reverse Engineering and New Product Development. Upper Saddle River: Prentice-Hall, 2001. p. 357-410.

SUH, N. P. The Principles of Design. New York: Oxford University Press, 1990.

TSENG, H. E.; CHANG, C. C.; Ll, J. D. Modular design to support green life-cycle engineering. Expert Systems with Applications, v. 34, p. 2524-2537, 2008. http://dx.doi. org/10.1016/j.eswa.2007.04.018

ULlMAN, D. G. The Mechanical Design Process. 3rd ed. New York: McGraw-Hill, 2003.

ULRICH, K. The Role of Product Architecture in the Manufacturing Firm. Research Policy, v. 24, n. 3, p. 419-440, 1995. http://dx.doi.org/10.1016/00487333(94)00775-3

ULRICH, K.; TUNG, K. Fundamentals of Product Modularity. In: CONFERENCE ON DESIGN MANUFACTURE/ INTEGRATION, 1991, Miami. Proceedings... Miami, 1991.

ULRICH, K. T.; EPPINGER, S. D. Product Design and Development. 3rd ed. New York: McGraw-Hill/ Irwin, 2004.

VAN WIE, M. et al. Representing Product Architecture. In: ASME DESIGN ENGINEERING TECHNICAL CONFERENCES - DESIGN THEORY AND METHODOLOGY CONFERENCE, Chicago, 2003. Proceedings... Chicago, 2003.

WANG, C. S. Web-based modular interface geometries with constraints in assembly models. Computers \& Industrial Engineering, v. 56, p. 1675-1686, 2009. http://dx.doi. org/10.1016/j.cie.2008.10.018

WHITNEY, D. E. Mechanical Assemblies: Their Design, Manufacture, and Role in Product Development. New York: Oxford University Press, 2004.

WIENDAHL, H. P. et. al. Changeable Manufacturing - Classification, Design and Operation. Annals of the CIRP, v. 56, n. 2, p. 783-809, 2007. http:// dx.doi.org/10.1016/j.cirp.2007.10.003

ZENG, Y. Environment-based formulation of design problem. Transactions of the SDPS: Journal of Integrated Design and Process Science, v. 8, n. 4, p. 45-63, 2004.

\title{
Procedure for interface selection for modular products based on the product design cycle
}

\begin{abstract}
This paper deals with the definition of interface alternatives during the development of modular products. Interfaces could be seen as the boundary between modules, as well the existing interactions with the surrounding environment and possible users. In order to carry out interface design, a procedure to aid in the conception of interface alternatives and their ranking is proposed, assisting the design team on decision-making. The procedure proposed was validated during the design of modular products for mussel farming and processing in the State of Santa Catarina. The results achieved show the potential of this design tool.
\end{abstract}

\section{Keywords}

Modular design. Interface design. Product development. 